\title{
The Effectiveness of a Parent Involvement-Child Behavioral Management Program on Attention Deficit Hyperactivity Disorder Symptoms among Thai School-age Children
}

\author{
Ubon Wannakit, M.S. ${ }^{1}$, Jintana Yunibhand, Ph.D., Dip. APPMHN², \\ Chanokporn Jitpanya, Ph.D. ${ }^{2}$ \\ ${ }^{1}$ Faculty of Nursing, Prince of Songkla University, Pattani Campus, Mueang, Pattani 94000, Thailand. \\ ${ }^{2}$ Faculty of Nursing, Chulalongkorn University, Pathum Wan, Bangkok 10330, Thailand. \\ Received 7 July 2021 • Revised 10 November 2021 • Accepted 1 December 2021 • Published online 27 January 2022
}

\begin{abstract}
:
Objective: This study examined effect of a new Parent Involvement-Child Behavioral Management Program (PICBMP) on Attention Deficit Hyperactivity Disorder (ADHD) symptoms (inattention, hyperactivity, impulsivity) among school-age children with ADHD in a regional psychiatric hospital in Thailand.
\end{abstract}

Material and Methods: In this pretest-posttest control group study, 60 children between 6 and 12 years of age diagnosed with $\mathrm{ADHD}$ and their parents were equally and randomly assigned to either the PICBMP or usual care group. The individuals assigned to the PICBMP group attended an 8-week of behavior management program for parents of ADHD children, which was in addition to a usual care program, while usual care was provided to individuals only provided to the control group. The Swanson, Nolan, and Pelham-IV tool was used to evaluate the ADHD symptoms in all children before and after the PICBMP intervention. Descriptive statistics and t-test were used for data analysis $(p-v a l u e<0.050)$. Results: Most of the children were male $-75.0 \%$, and $-88.4 \%$ of the parents in the study were female. The average age of the children was 8.9 years (S.D.=1.67), and that of the parents was 40 years (S.D.=6.17). Significantly lower ADHD symptoms were found in the children who received the PICBMP compared to the children who received the usual care at pretest and posttest $(t=-5.065, p$-value<0.050). The ADHD symptoms in the children in the intervention experimental group significantly decreased after their parents attended the PICBMP ( $t=14.986, p-v a l u e<0.050)$.

Conclusion: The findings of this study support the effectiveness of the PICBMP in reducing ADHD symptoms.

Keywords: Attention Deficit Hyperactivity Disorder symptoms, behavior management, parent involvement, school-age children

Contact: Assoc. Prof. Dr. Jintana Yunibhand, Ph.D., Dip. APPMHN

Faculty of Nursing, Chulalongkorn University, Pathum Wan, Bangkok 10330, Thailand.

E-mail: yuni_jintana@hotmail.com

(c) 2022 JHSMR. Hosting by Prince of Songkla University. All rights reserved.

This is an open access article under the CC BY-NC-ND license

(http://www.jhsmr.org/index.php/jhsmr/about/editorialPolicies\#openAccessPolicy).
J Health Sci Med Res 2022;40(5):509-518 doi: 10.31584/jhsmr.2022860 www.jhsmr.org 


\section{Introduction}

Attention Deficit Hyperactivity Disorder (ADHD) is a disorder affecting 5.0 to $12.0 \%$ of children worldwide ${ }^{1}$, and $8.1 \%$ of Thai school-age children. ${ }^{2}$ ADHD consists of three core symptoms, inattention, hyperactivity, and impulsivity. ${ }^{1}$ These core symptoms cause severe problems in schoolage children. They can persist into adolescence and can lead to drug abuse and long-term economic burden. ${ }^{3}$ The family burden associated with ADHD comprises an individual's illness, direct costs relating to the child's behaviors, indirect costs relating to caregiver strain, and intangible costs such as an increased risk of parenting stress, difficulties with parent-child and sibling interactions, marital discord, parental depression, and alcohol-related problems. ${ }^{4}$ These impacts are critical problems in children if they do not get adequate treatment at school-age.

To establish an effective intervention, identification of factors associated with ADHD symptoms is required. Several studies have found that factors associated with ADHD symptoms were child factors and parent factors. ${ }^{5-7}$ The main child factors include comorbidity disorder aggressive behavior, and socially inappropriate behavior and the main parental factors include parental stress and parenting practices. ${ }^{8-10}$

Many studies have reported that behavioral management can reduce ADHD symptoms ${ }^{11-14}$, and significant improvements have been found following behavioral management programs with parental involvement. ${ }^{15,16}$ Also, parenting support and involvement have led to significant improvements in children with ADHD. ${ }^{17,18}$ Behavioral management focuses on targeting behavioral alterations to amplify the rate and density of desired behaviors and decrease unwanted behaviors in children. ${ }^{13,19}$ It requires parental involvement and continual improvement of parental skills in child raising. ${ }^{20,21}$

Most of the available reports of behavioral management in Thailand have several limitations: 1) they mainly focus on one core symptom, not on the three core symptoms (inattention, hyperactivity, impulsivity) ${ }^{22}$; 2) some study interventions have occurred with parents while some with children; no study intervention to date has combined both parents and children ${ }^{2,22}$; and 3) most of them cover only some steps of behavioral management with no parents involved in the program. ${ }^{23}$

To address these problems, this study trialed used behavioral management with parental involvement focusing on the main trio of ADHD symptoms, inattention, hyperactivity, and impulsivity, and including the Oppositional Defiant Disorder (ODD) symptoms. Since ODD can cooccurswith ADHD, the evaluation of ADHD symptoms as the treatment results assessment should include ODD symptoms. $^{3}$

The behavior-based treatment program outlined by Goodman and $\mathrm{Scott}^{19}$ is a practical model of behavioral management for children with behavior problems. The treatment combines teaching the parents new behavioral management skills for dealing with their children combined with and their relationship with their children with operant conditioning and social learning theory. Operant conditioning includes response-contingent effects using positive and negative reinforcement and extinction. In social learning theory, parents learn behavior modification techniques for building good relationships with their children. Behavioral management includes (i) behavior analysis: assessments carefully concentrate on what happens in the present, (ii) identification of target behaviors with parents and children, (iii) behavior modification techniques (increasing desired behaviors, decreasing undesired behaviors, (iv) implementation (planning, maintaining all techniques), and ( $v$ ) evaluating the whole behavioral management process. ${ }^{19}$ These evaluation steps are feasibility, practice flexibility, and theoretical concepts to identify child behavior problems which also require parental involvement. The Parent Involvement-Child Behavioral Management Program 
(PICBMP) was developed from the practical guide of behavior-based treatment. This program aims to reduce behavioral problems associated with ADHD symptoms for children with $A D H D$, educate parents on child behavior management, and improve parenting skills in childcare.

This study aimed to compare differences in ADHD symptoms between the children with ADHD in the intervention group and the no-intervention control group.

Numerous randomized clinical trials, systematic reviews, and meta-analyses in western countries have shown a positive effect of behavior management and parental involvement on ADHD symptoms. ${ }^{11,24,25}$ Therefore, this study hypothesized that 1) the symptom scores obtained by children with $A D H D$ in the intervention group would significantly decrease after the program, and 2) the symptom scores obtained by the children in the intervention group would be significantly lower than in those who received only the usual care.

\section{Material and Methods}

This pretest-posttest control group study was conducted at the Child and Adolescent Psychiatric Clinic of a regional psychiatric hospital in Thailand.

The participants were children with ADHD and their parents. The sample size was calculated using the power analysis of 0.80 , the effect size determination based on previous studies of behavioral management in children was around $0.40-0.55^{26,27}$, with a significance level of 0.050 . The resulting required sample size per group was 29. After considering a $10.0 \%$ attrition rate, we needed 32 participants per group (total of 64).

Inclusion criteria: The included children were a) 6-12 years of age who were treated at the Child and Adolescent Psychiatric Clinic; b) who were diagnosed with ADHD, and $c$ ) who had no comorbid disorders or other developmental disorders. The parental criteria were a) a father or mother or caregiver (relative), b) who had continuously taken care of the child for at least 6 months, and c) able to communicate well in Thai.

Exclusion criteria: children or a parent/caregiver who had a physical illness (infection, disease, current accident), and/or any mental health disorder (bipolar disorder, self-injurious behavior or chronically suicidal), and/or substance dependence) within the past 6 months were excluded.

Purposive sampling and simple random sampling were used to select participants following the inclusion criteria from the medical records of the HosXp database. Of 690 children aged 6-12 years diagnosed with ADHD, 420 children had comorbid disorders and were excluded. A random number table was used to assign the participants to either the intervention-group or the control group. All children had psychological and basic physical examinations conducted by a psychiatrist. The parents were interviewed about their medical history and mental health screenings by the researcher. 32 children in the intervention group received the PICBMP for 8 weeks, while 32 children in the control group obtained the usual care. All children received methylphenidate hydrochloride (Ritalin) as medication and the usual care from a child psychiatric clinic. The total number of participants at the end of the program was 60 because four children dropped out (two children in the intervention group could not attend through 8 weeks, and two children in the control group refused to complete the posttest). To control contamination between the two groups, the participants in the two groups were given appointments to meet their doctors on different days to ensure that they did not meet each other.

The PICBMP was approved by 5 experts (2 psychiatrists, 2 nurse educators, and 1 advanced psychiatric nurse). To investigate the feasibility and robustness of this program, a pilot study was conducted among 8 children with $\mathrm{ADHD}$ and their parents. All participants, including the research assistants who used the program, were interviewed 
and provided feedback on the program. The PICBMP was then revised as follows: develop situations as examples of behavior analysis, record details of group activities step by step, add more discussion sessions with the parents, and add the details of behavior modification techniques such as positive and negative reinforcement, and overcorrection token economy.

The PICBMP comprises 4 phases in an 8-week program. The program consists of 8 sessions, one session per week. The details regarding the PICBMP program were as follows: The three therapists who carried out the data collection were psychiatric nurses who had a master's degree in mental health psychiatric nursing, had more than 5 years in child and adolescent psychiatric nursing, and were trained in behavior modification techniques. The first therapist provided behavior modification for the children and managed the program. The second therapist conducted the group activities for the children and the third therapist assessed and recorded the children's behaviors. The children were divided into 3 groups by age (6-9 years, 2 groups and 9-12 years, 1 group). All groups followed the activities of the same therapist. Following each sessionthe three therapists discussed what had happened. In each session, behavior modification techniques were employed whenever a child showed behavioral problems while parents observed the process and the various techniques were taught through group discussion. Both the children and the parents were assigned homework. Parents were encouraged to practice behavioral management at home by counseling through the Line application. Phase 1 (week 1: 3-hours): assessing the needs of parents, their preparedness, problems, and ADHD knowledge, and educating them concerning relevant ADHD knowledge, caring for children with ADHD, behavioral management, and behavior modification techniques.

Phase 2 (week 1: 1-hour): assessing and analyzing behavior problems through parent and children interviews. Setting the behavior management goals with the parents and children.
Phase 3 (weeks 2-7: 3-hours weekly session): practicing behavior modification techniques through group activities and behavior modification techniques. Also developing parental behavior modification skills and parent-child interaction techiniques. This included assigning homework to parents and children, encouraging the parents to carry out behavioral modification practices at home, and being part of the Line group for consultation-purposes. The group activities differed between age groups (6-9 years, and 9-12 years). The parents observed their child during the group activities, and they often joined the group during break times to have a beverage with their child and to have further positive interactions.

Phase 4 (week 8: 3-hours weekly session): the program was evaluated in this phase using focus groups. The parents were encouraged to continue the program in the future.

\section{Measurements}

1. The Swanson, Nolan, and Pelham-IV (SNAPIV) Scale was developed by SNAP and is based on the diagnostic criteria of the Diagnostic and Statistical Manual of Mental Disorders-IV. The instrument comprises 26 items, 18 examining ADHD (9 inattention and 9 hyperactivity/ impulsivity) and 8 examining ODD. The three symptom subsets (inattention, hyperactivity/impulsivity, and ODD) are scored by assigning a severity estimate using a 4-point scale. ${ }^{28}$ The scores were calculated by summing the scores on the subset items ${ }^{-}$and dividing by the number of subset items. The SNAP-IV instrument was previously translated into a Thai version and tested for psychometric properties by a team of child psychiatrists. The cronbach's alpha of the original version was $0.93-0.96 .^{29}$ In this study, the CVI of 5 experts' ratings on the SNAP-IV was 1. A pilot test was conducted to estimate the reliability among 30 parents of the ADHD children (cronbach's alpha=0.76). The parents who did not participate in the program rated the SNAP-IV before and after the experimentation. 
2. Instruments used in the intervention: the Strengths and Difficulties Questionnaire (SDQ) and the Overt Aggression Scale (OAS) were used to assess the behavioral problems and aggressive behaviors during experimentation.

2.1 The SDQ includes 25 items and was completed by the of children 4-16 years of age. ${ }^{30}$ The Thai version of the SDQ was previously tested for its psychometric properties and was found to have good validity and reliability ${ }^{29}$ with cronbach's alpha of 0.70-0.90. The SDQ was tested with content validity index $(\mathrm{CVI})=0.90$ and cronbach's alpha $=0.73$.

2.2 The OAS is divided into four parts with 9 items assessing aggressive behavior: 1) verbal aggression, 2) physical aggression against self, 3) physical aggression against objects, and 4) physical aggression against others. ${ }^{31}$ The Thai version of the OAS has been tested for psychometric properties. $^{32}$ In this study, the CVI was 0.83 and the cronbach's alpha 0.80 .

During the intervention, behavior problems were assessed by the research assistant using both the SDQ and OAS. Over the 8 weeks of behavioral management training, the frequency of behavior problems continuously decreased. For example, restlessness decreased from 18 times in the first week to once in the last week. The behaviors of "cannot finish the task," "blurting out," and "do not wait for their turn" decreased from 16, 12, and 10 to 0,1 , and 0 from the first week to the last week, respectively. The average frequency of verbal aggression decreased from 4 times in the first week to zero in the last week. Shouting, pushing others, and physical harm all decreased from 2 times in the first week to zero in the last week.

The study was approved by the Institutional Review Board of the Psychiatric Hospital (date: 30/08/2019, number 10/2019). The PICBMP details were explained to the participants before signing the consent and assent forms. They were also allowed and had the right to stop being part of the program at any point in time without facing any consequences.

The study data were analyzed using SPSS software. chi-square was used to test the differences in the characteristics of the two group. Paired t-test was used to compare differences in ADHD symptoms in the intervention group before and after the trial. Independent t-test was used to compare pretest and posttest ADHD symptom scores between the control group and the intervention group.

\section{Results}

1. Characteristics of participants: the majority of the 60 study ADHD children were 9-12 years old $53.3 \%$ ), with a majority of the intervention group was 6-9 years old $(63.3 \%)$. Most of the children were male, at $73.3 \%$ and $76.7 \%$ in the control and intervention groups, respectively. Chi-square tests showed no statistically significant differences between the children and parents in the control and the intervention groups regarding gender, age, education, and occupation (Table 1).

\section{Comparisons within the intervention group} at pretest and posttest: The t-test showed a significant difference in ADHD symptoms in the children before and after completing the PICBMP. All mean ADHD symptoms scores, inattention ( $t=9.93)$, hyperactivity/impulsivity $(t=12.54)$, and ODD ( $t=6.03)$, were significantly decreased after completion of the PICBMP at the significance level of p-value $<0.050$ (Table 2).

\section{Comparison between the intervention and} control groups at pretest and posttest: The results of the analysis showed significant pre-posttest differences in ADHD symptoms between the control and intervention groups. The children in the intervention group were significantly lower than those who received only usual care during the study. Inattention and hyperactivity/impulsivity symptoms significantly decreased after the PICBMP study when compared to the usual care alone group. However, 
no significant differences were found in the ODD symptoms between the control and intervention groups before and after the intervention (Table 3).

In the post-intervention focus group, we found that most of the parents were very happy with the program. They also said they were satisfied with the Line group, with which they used an average of 5-8 posts per day giving their opinions/information or asking questions of the other participants. The most common questions were about behavior modification, techniques of taking care of children, and positive communication with children.

Table 1 Children and parent demographic characteristics

\begin{tabular}{|c|c|c|c|c|}
\hline Characteristic & $\begin{array}{l}\text { Control }(n=30) \\
\text { Number }(\%)\end{array}$ & $\begin{array}{l}\text { Intervention }(\mathrm{n}=30) \\
\text { Number }(\%)\end{array}$ & $X^{2}(d f)$ & $\mathrm{p}$-value \\
\hline \multicolumn{5}{|l|}{ Children's characteristics } \\
\hline \multicolumn{5}{|l|}{ Gender } \\
\hline Boys & $22(73.3)$ & $23(76.7)$ & \multirow[t]{2}{*}{0.089} & \multirow[t]{2}{*}{0.766} \\
\hline Girls & $8(26.7)$ & $7(23.3)$ & & \\
\hline \multicolumn{5}{|l|}{ Age (years old) } \\
\hline $6-9$ & $14(46.7)$ & 19 (63.3) & \multirow[t]{3}{*}{1.684} & \multirow[t]{3}{*}{0.194} \\
\hline $9-12$ & $16(53.3)$ & $11(36.7)$ & & \\
\hline Mean $=8.97$, S.D. $=1.67$ & $9.05(1.8)$ & $8.88(1.5)$ & & \\
\hline \multicolumn{5}{|c|}{ Person taking care of children } \\
\hline Father and mother & $22(73.3)$ & $18(60.0)$ & \multirow[t]{4}{*}{0.283} & \multirow[t]{4}{*}{0.186} \\
\hline Only mother & $3(10.0)$ & $8(26.7)$ & & \\
\hline Only the father & $2(6.7)$ & $0(0.0)$ & & \\
\hline Relative & $3(10.0)$ & $4(13.3)$ & & \\
\hline \multicolumn{5}{|l|}{ Parent's characteristics } \\
\hline \multicolumn{5}{|l|}{ Gender } \\
\hline Male & $4(13.3)$ & $3(10.0)$ & \multirow[t]{2}{*}{0.162} & \multirow[t]{2}{*}{0.688} \\
\hline Female & $26(86.7)$ & $27(90.0)$ & & \\
\hline \multicolumn{5}{|l|}{ Age (years old) } \\
\hline $25-35$ & $8(26.7)$ & $4(13.3)$ & \multirow[t]{4}{*}{2.179} & \multirow[t]{4}{*}{0.336} \\
\hline $36-45$ & $18(60.0)$ & 19 (63.3) & & \\
\hline $46-60$ & $4(13.3)$ & 7 (23.3) & & \\
\hline Mean $=40$, S.D. $=6.17$ & $40(6.1)$ & $41.5(5.3)$ & & \\
\hline \multicolumn{5}{|l|}{ Education } \\
\hline Primary school & $1(3.3)$ & $2(6.7)$ & \multirow[t]{5}{*}{1.059} & \multirow[t]{5}{*}{0.901} \\
\hline High school & 4 (13.3) & $2(6.7)$ & & \\
\hline Diploma & $8(26.7)$ & $9(30.0)$ & & \\
\hline Bachelor degree & $15(50.0)$ & $15(50.0)$ & & \\
\hline Master degree/higher & $2(6.7)$ & $2(6.7)$ & & \\
\hline \multicolumn{5}{|l|}{ Occupation } \\
\hline Government official & $16(53.3)$ & $14(46.7)$ & \multirow[t]{5}{*}{1.911} & \multirow[t]{5}{*}{0.861} \\
\hline Company employee & $2(6.7)$ & $4(13.3)$ & & \\
\hline Agriculture & $1(3.3)$ & $0(0.0)$ & & \\
\hline Businessman/merchant & $4(13.3)$ & $5(16.7)$ & & \\
\hline General employee & 7 (23.3) & 7 (23.3) & & \\
\hline
\end{tabular}

S.D.=standard deviation 
Table 2 Comparison of ADHD symptoms before and after receiving the intervention

\begin{tabular}{|c|c|c|c|c|c|c|c|}
\hline \multirow{2}{*}{$\begin{array}{l}\text { ADHD } \\
\text { symptoms }\end{array}$} & \multicolumn{2}{|c|}{ Pretest } & \multicolumn{2}{|c|}{ Posttest } & \multirow{2}{*}{$t$} & \multirow{2}{*}{ df } & \multirow{2}{*}{$p$-value } \\
\hline & Mean & S.D. & Mean & S.D. & & & \\
\hline Inattention & 17.50 & 2.080 & 14.56 & 1.977 & 9.933 & 29 & $0.001^{*}$ \\
\hline Hyperactivity/impulsivity & 14.63 & 2.311 & 12.26 & 2.362 & 12.544 & 29 & $0.001^{*}$ \\
\hline Opposition/defiance & 11.86 & 2.510 & 10.33 & 2.468 & 6.030 & 29 & $0.001^{*}$ \\
\hline
\end{tabular}

*Variable statistically significant ( $\mathrm{p}$-value<0.050). Inattention and hyperactivity/impulsivity subset scores were rated as sum of scores $0-27$, opposition/defiance subset was rated as sum of scores 0-24. A higher score shows greater severity, lower scores show improvement of symptoms. $\mathrm{Cl}=.95$

S.D.=standard deviation, ADHD=Attention Deficit Hyperactivity Disorder

Table 3 Comparison of ADHD symptoms between interventionand control groups

\begin{tabular}{|c|c|c|c|c|c|c|c|c|}
\hline \multirow{2}{*}{\multicolumn{2}{|c|}{$\begin{array}{l}\text { ADHD } \\
\text { Symptom }\end{array}$}} & \multicolumn{2}{|c|}{ PICBMP } & \multicolumn{2}{|c|}{ Usual care } & \multirow{2}{*}{$t$} & \multirow{2}{*}{ df } & \multirow{2}{*}{ p-value } \\
\hline & & Mean & S.D. & Mean & S.D. & & & \\
\hline \multirow[t]{2}{*}{ Inattention } & Pretest & 17.50 & 2.080 & 17.40 & 2.130 & 0.181 & 58 & 0.857 \\
\hline & Posttest & 14.56 & 1.977 & 17.30 & 2.086 & -5.208 & 58 & $0.001^{*}$ \\
\hline \multirow[t]{2}{*}{ Hyperactivity/impulsivity } & Pretest & 14.63 & 2.311 & 14.53 & 2.300 & 0.168 & 58 & 0.867 \\
\hline & Posttest & 12.26 & 2.362 & 14.40 & 2.313 & -3.534 & 58 & $0.001^{*}$ \\
\hline \multirow[t]{2}{*}{ Opposition/defiance } & Pretest & 11.80 & 2.510 & 11.36 & 2.355 & 0.689 & 58 & 0.493 \\
\hline & Posttest & 10.33 & 2.468 & 11.30 & 2.365 & -1.549 & 58 & 0.127 \\
\hline
\end{tabular}

*Variable statistically significant ( $p$-value<0.050) Inattention and hyperactivity/impulsivity subset scores were rated as sum score $0-27$, opposition/defiance subset was rated as sum score 0-24. The higher score shows great severity, the lower score showing improvement of symptoms. $\mathrm{Cl}=.95$

PICBMP=Parent Involvement-Child Behavioral Management Program, S.D.=standard deviation, ADHD=Attention Deficit Hyperactivity Disorder

\section{Discussion}

This paper describes the successful implementation of the PICBMP intervention to reduce ADHD symptoms in children with ADHD. The intervention was developed from a behaviorally-based treatment proposed by Goodman and Scott to address the efficacy of parent involvement in the behavioral management of ADHD in Thai children.

A pretest-posttest control group design was used to assess the success of behavior management. The study participants were randomly assigned to either the PICBMP or usual care groups. This study found that the PICBMP successfully reduced ADHD symptoms, which compares very favorably with previous studies. ${ }^{16,25,27,33,34}$ The posttest ADHD symptoms scores in the intervention group were significantly lower than in the control group. The PICBMP demonstrated a statistically significant and clinically substantial improvement in the inattention and hyperactivity/impulsivity symptoms. This might be because the parents in the intervention group gained experience from participating in the program in behavior modification techniques and discussed it with the therapist and the others in the intervention group. The overall ADHD symptom score (SNAP-IV) at the posttest (1 month after the program finished) was 1.40 (the mean score, calculated by a total of 
3 subset/items), which is lower than the scores obtained by Döpfner et al. (2020) on the SNAP-IV rating scale, which was $1.44 .^{35}$ However, when compared to the eight-year follow-up, the score obtained by Döpfner et al. (2020) was 0.78 , which is lower than the score obtained in this study. Thus, additional research is needed to evaluate the longterm results of the PICBMP.

These findings confirm the effect of behavioral management on inattention and hyperactivity/impulsivity symptoms. Our results are similar to studies that reported a positive effect in reducing inattentive, hyperactive, and oppositional behaviors when parent and child training were combined for children with ADHD..$^{11,24,36,37}$ We found that behavior modification techniques were effective in teaching children with ADHD to control themselves. The children in the intervention group showed improved ability to concentrate on their assignments and wait for the group the PICBMP strategy assisted children to learn to control themselves and also guided parents in how to practice behavior modification at home. Also, the results from the focus group analysis indicated that parents found the program helpful and worthwhile. They also benefitted from the Line group communication because they could consult the therapist anytime. However, the findings indicate that improving ODD symptoms might require a lengthier time to improve, as found in the studies of Molina et al. ${ }^{38}$ and Webster-Stratton et al. ${ }^{39}$

This program can serve as a guideline for psychiatric nurses to apply behavioural management techniques in the clinic. The results of the focus group suggests the need to carry out the program on an ongoing basis in the clinic.

There were some limitations to this study. Firstly, the children in the intervention group were younger than those in the control group. In addition, the parents in this study were all well-educated and had good socioeconomic status which could have influenced the outcomes. Thirdly, the research assistant rated the SDQ and OAS scores, which may have introduced information bias. Fourthly, although the score of ODD symptoms after completing the program was significant (Table 3), the difference between the scores was very low and may not meet clinical significance. Finally, even though the parents who rated the SNAP-IV had to be another person from the one who participated in the program which may have affected the results. Therefore, the teacher should evaluate the outcome measures. For future studies, additional research is needed to empirically evaluate the implementation of this program in other settings to compare the results and confirm the program's rigor, including evaluating various social skills and academic performance outcomes rather than ADHD symptoms alone.

\section{Conclusion}

The current study provides preliminary support for the applicability and acceptability of the PICBMP. This program can be used to promote early parent involvement in behavioral-based interventions in children with ADHD. Even though the study found that the PICBMP had limitations, it still showed good success in modifying behavioral problems in ADHD children by increasing desirable behaviors and reducing aggressive, distractive, and socially inappropriate behaviors. It also improved parental skills and knowledge to help them positively modify their ADHD children's problems. The procedures of this program can be flexibly integrated into routine nursing care.

\section{Acknowledgment}

The study was supported by the health care staff at Songkhla Rajanagarindra Psychiatric Hospital and their assistance with data collection.

\section{Funding sources}

The study was supported by a research promotion grant from Chulalongkorn University in 2019 and the Office of Higher Education Commission in 2017. 


\section{Conflict of interest}

The authors report no actual or potential conflicts of interest.

\section{References}

1. Thomas R, Sanders S, Doust J, Beller E, Glasziou P. Prevalence of attention-deficit/hyperactivity disorder: a systematic review and meta-analysis. Pediatr 2015;4:e994-1001.

2. Visanuyothin $T$, Pavasuthipaisit $C$, Wachiradilok $P$, Arunruang $\mathrm{P}$, Buranasuksakul T. The prevalence of attention deficit/ hyperactivity disorder in Thailand. J Ment Health Thai 2013; 21: 66-75.

3. Adler LA, Spencer TJ, Wilens TE. Attention-deficit hyperactivity disorder in adult and children. Cambridge: Cambridge University Press; 2015.

4. Zhao X, Page TF, Altszuler AR, Pelham WE, Kipp H, Gnagy EM, et al. Family burden of raising a child with ADHD. J Abnorm Child Psychol 2019;8:1327-38.

5. Tsai CJ, Chen YL, Lin HY, Gau SSF. One-year trajectory analysis for ADHD symptoms and its associated factors in community-based children and adolescents in Taiwan. Child Adolesc Ment Health 2017;11:1-11.

6. Biederman J, Petty CR, Clarke A, Lomedico A, Faraone SV. Predictors of persistent ADHD: an 11-year follow-up study. J Psychiat Res 2011;45:150-5.

7. Esra Çöp, S Ebru Çengel Kültür, Gülser Şenses Dinç. Association between parenting styles and symptoms of deficit hyperactivity disorder. Turk Psikiyatri Derg 2017;28: 25-32.

8. Ardıç UI, Uysal T, Başay Br, Ercan Ep, Ercan E, İnci S, et al. Predicting aggression in children with ADHD. Child Adolesc Psychiatry Ment Health 2014;8:1-10.

9. Staikova E, Gomes H, Tartter V, McCabe A, Halperin JM. Pragmatic deficits and social impairment in children with ADHD. J Child Psychol Psychiatry 2013;12:1275-83.

10. Sasser TR, Kalvin CB, Bierman KL. Developmental trajectories of clinically significant attention-deficit/hyperactivity disorder (ADHD) symptoms from grade 3 through 12 in a high-risk sample: Predictors and outcomes. J Abnorm psychol 2016;2: 207-19.

11. Coles EK, Pelham lii WE, Fabiano GA, Gnagy EM, BurrowsMacLean L, Wymbs BT, et al. Randomized trial of first-line behavioral intervention to reduce need for medication in children with ADHD. J Clinical Child Adolesc Psychol 2019; 53:1-15.

12. Mitchell J. Behavioral Approach in ADHD. J Atten Disord 2010; 6:609-17.

13. Lessing AC, Wulfsohn R. The potential of behaviour management strategies to support learners with attention deficit hyperactivity disorder in the classroom. Educ As Change 2015;19: 54-77.

14. Rajeh A, Amanullah S, Shivakumar K, Cole JQEHPEIC. Interventions in ADHD: A comparative review of stimulant medications and behavioral therapies. Asian J Psychiat 2017;25:131-5.

15. Pfiffner LJ, Haack LM. Behavior management for school-aged children with ADHD. Child Adolesc Psychiat Clin 2014;23: 731-46.

16. DuPaul GJ, Kern L, Belk G, Custer B, Hatfield A, Daffner M, et al. Promoting Parent Engagement in Behavioral Intervention for Young Children with ADHD: Iterative Treatment Development. Topics Early Child Spec Educ 2018;38:42-53.

17. Montes G, Montes SA. Parental involvement of parents of children with ADHD: a first population study. J Atten Disord 2020;19:1-9.

18. Shelleby EC, Ogg J. Longitudinal relationships between parent involvement, parental warmth, ADHD symptoms, and reading achievement. J Atten Disord 2020;5:737-49.

19. Goodman R, Scott S. Behaviorally-based treatments. In: Goodman R, editor. Child and adolescent psychiatry. Chichester, West Sussex: Wiley- Blackwell; 2012.

20. Pelham WE, Fabiano GA, Waxmonsky JG, Greiner AR, Gnagy EM, Pelham lii WE, et al. Treatment sequencing for childhood ADHD: a multiple-randomization study of adaptive medication and behavioral interventions. J Clin Child Adolesc Psychol 2016;4:396-415.

21. Rogers MA, Wiener J, Marton I, Tannock R. Parental involvement in children's learning: comparing parents of children with and without Attention-Deficit/Hyperactivity Disorder (ADHD). J Sch Psychol 2009;3:167-85.

22. CAMRI. Clinical practice guideline of Children with ADHD for multidisciplinary team. In: health caAm, editor. Bangkok: CAMRI; 2016;p.80.

23. Kanlaya $P$, Yunibhand J. The effect of an aggressive behavior management program in children with attention deficit hyperactivity disorder. Royal Thai Navy Med J 2019;3:522-35. 
24. Daley D, Van der Oord S, Ferrin M, Danckaerts M, Doepfner $\mathrm{M}$, Cortese $\mathrm{S}$, et al. Behavioral interventions in attentiondeficit/hyperactivity disorder: a meta-analysis of randomized controlled trials across multiple outcome domains. J Am Acad Child Adolesc Psychiatry 2014;8:835-47.

25. Evans SW, Owens JS, Wymbs BT, Ray AR. Evidence-based psychosocial treatments for children and adolescents with attention deficit/hyperactivity disorder. J Clin Child Adolesc Psychol 2018;2:157-198.

26. Evans SW, Owens JS, Bunford N. Evidence-based psychosocial treatments for children and adolescents with attention-deficit/ hyperactivity disorder. J Clin Child Adolesc Psychol 2014;43: 527-51.

27. Fabiano GA, Pelham Jr WE, Coles EK, Gnagy EM, ChronisTuscano A, O'Connor BC. A meta-analysis of behavioral treatments for attention-deficit/hyperactivity disorder. Clin Psychol Rev 2009;2:129-40.

28. Swanson JM. School-based assessments and interventions for ADD students. Irvine, CA: KC Publishing; 1992.

29. Pityaratstian N, Booranasuksakul T, Juengsiragulwit D, Benyakorn S. ADHD screening properties of the Thai version of Swanson, Nolan, and Pelham IV scale (SNAP-IV) and Strengths and Difficulties Questionnaire (SDQ). J Psychiatr Assoc Thai 2014;2:97-110.

30. Goodman R. The strengths and difficulties questionnaire: a research note. J Child Psychol Psychiatry 1997;38:581-6.

31. Yudofsky SC, Silver JM, Jackson W, Endicott J, Williams D. The Overt Aggression Scale for the objective rating of verbal and physical aggression. Am J Psychiatry 1986;43:35-39.

32. Thongpetch $U$, Yunibhand J. The effect of behavior therapy on aggressive behaviors of autistic children, out patient. J Psychiat Nur Ment Health 2012;26:86-97.

33. Mohammed F. Effects of a tailored incredible years teacher classroom management programme on on-task behaviour of school children with ADHD in Addis Ababa. J Int Spec Needs Educ 2018;1:1-3.

34. Veenman B, Luman M, Hoeksma J, Pieterse K, Oosterlaan J. A randomized effectiveness trial of a behavioral teacher program targeting ADHD symptoms. J Atten Disord 2019;3: 293-304.

35. Döpfner M, Ise E, Breuer D, Rademacher C, Metternich-Kaizman TW, Schürmann S. Long-term course after adaptive multimodal treatment for children with ADHD: an 8-year follow-up. J Atten Disord 2020;1:145-62.

36. Mohammadi MR, Soleimani AA, Ahmadi N, Davoodi E. A comparison of effectiveness of parent behavioral management training and methylphenidate on reduction of symptoms of attention deficit hyperactivity disorder. Acta Med Iran 2016;8:503-9.

37. Williford AP, Shelton TL. Behavior management for preschoolaged children. Child Adolesc Psychiatric Clin 2014;4:717-30.

38. Molina BSG, Hinshaw SP, Swanson JM, Arnold LE, Vitiello B, Jensen PS, et al. New research: the MTA at 8 years: prospective follow-up of children treated for combined-type ADHD in a multisite study. J Am Acad Child Adolesc Psychiatry 2009;48: 484-500.

39. Webster-Stratton $\mathrm{CH}$, Reid MJ, Beauchaine T. Combining parent and child training for young children with ADHD. J Clin Child Adolesc Psychol 2011;2:191-203. 